\title{
USO DO AGREGADO GRAÚDO RECICLADO CLASSE A NA FABRICAÇÃO DE CONCRETOS CONVENCIONAIS PARA FINS GERAIS NA CONSTRUÇÃO CIVIL ${ }^{a}$
}

\author{
USE OF COARSE RECYCLED CLASS A AGGREGATES IN THE MANUFACTURE OF \\ CONVENTIONAL CONCRETES FOR GENERAL PURPOSES IN CIVIL CONSTRUCTION
}

Marcus Vinícius Fraga Lobo'

\begin{abstract}
A indústria da construção civil é a que mais gera resíduos sólidos, contribuindo com o agravamento da agressão ambiental através dos seus descartes inapropriados. Este trabalho apresenta um estudo sobre a reciclagem de agregados graúdos de resíduos da construção civil e demolição (RCD) do tipo classe A, para serem utilizados na fabricação de concretos convencionais para fins específicos ou mesmo na sua utilização em sub-base de rodovias. Devido à inexistência de uma usina de reciclagem de RCD na Bahia e Sergipe, os Agregados Graúdos Reciclados (AGR) utilizados nesta pesquisa foram oriundos de Guarulhos - São Paulo, obtidos conforme a NBR 15116/14. Os agregados foram submetidos inicialmente a um tratamento mecânico de catação, para eliminar contaminantes e peneiramento, para diminuir os finos. Em seguida foram feitas caracterizações físicas através dos ensaios de granulometria, massa unitária no estado solto, massa específica e material pulverulento.Os ensaios físicos indicaram que os agregados reciclados podem ser usados para a fabricação de concretos convencionais simples para serem aplicados em pavimentação, construção de passeios e ruas, casas populares e contensão de encostas, escolas municipais e meio fios, drenagem de águas pluviais, etc. Dessa forma, com o aprofundamento das pesquisas e adequação da NBR 6118, poderá ser viabilizada a utilização do AGR na produção de concretos reciclados convencionais para fins específicos e gerais, e consequentemente, ampliar o volume reciclado de resíduos da construção civil e demolição, minimizando os impactos negativos ambientais, gerando emprego e renda e melhorando as condições sócias e econômicas das comunidades do Recôncavo da Bahia.
\end{abstract}

Palavras-chave: Sustentabilidade. Agregado Graúdo Reciclado.

The construction industry generates high amounts of solid waste, contributing to the aggravation of the environmental problems through its inappropriate disposal. This work presents a study on the recycling of coarse aggregates of construction and demolition type $A$ waste (ACD), to be used in the manufacture of conventional concrete for specific purposes or even for its use in highway sub-bases. Thus, the objective of this study was to assess the physical and mechanical characteristic of ACD. Due to the lack of an RCD recycling plant in Bahia and Sergipe, the recycled aggregates (AGR) used in this research came from Guarulhos - São Paulo, obtained according to NBR 15116/14. They received initially a mechanical quenching treatment to eliminate contaminants, and sieving to eliminate the small sized particles. Afterwards, the physical characterization was carried out through particle size tests, unit mass in the loose state, specific mass and powdery material. Physical tests indicated that recycled aggregates can be used for the manufacture of simple conventional concretes to be used for paving, street construction, popular homes, embankment and hillside contention, public schools, rainwater drainage, etc. In this way, with the deepening of the research and adaptation of NBR 6118, the use of AGR in the production of conventional recycled concrete for specific and general purposes, and consequently increasing the recycled volume of construction and demolition waste, reducing negative environmental impacts, generating employment and income, and improving the social and economic conditions of the communities of Recôncavo da Bahia.

Keywords: Sustainability. Coarse Aggregate Recycling.

\footnotetext{
${ }^{\mathrm{a}}$ Trabalho apresentado no XV Seminário Estudantil de Pesquisa da FAMAM e selecionado pela comissão científica do evento para publicação. ${ }^{1}$ Mestre em Meio Ambiente e Desenvolvimento Regional. Docente de Física do Centro Educacional Maria Milza. Docente do curso de Engenharia Civil da FAMAM, Governador Mangabeira, BA. lobo-marcus@outlook.com. CV: http://lattes.cnpq.br/2670624689768500.
} 


\section{INTRODUÇÃO}

Segundo o CONAMA n. 307 (2002, p. 2), no parágrafo 1 do artigo $4^{0}$ "os resíduos da construção civil não poderão ser dispostos em aterros de resíduos domiciliares, em áreas de "bota fora", em encostas e nascentes, lotes vagos e em áreas protegidas por lei [...]". Para minimizar esses impactos ambientais e reduzir o custo final da edificação, tem-se buscado novas metodologias construtivas no sentido de diminuir as perdas dos materiais manipulados, como também o aprofundamento dos estudos na reutilização dos resíduos da construção civil e demolição.

Pinto (1999) considerou uma massa de materiais de $1.200 \mathrm{~kg} / \mathrm{m}^{2}$ para edificações finalizadas e executadas predominantemente por processos tradicionais, e uma perda média de materiais nos processos construtivos de $25 \%$ em relação à massa de materiais que chegam ao canteiro de obra, com um percentual de perdas de materiais removidos como resíduos da construção civil (RCC) de 50\%, chegando assim a taxa de $150 \mathrm{~kg} / \mathrm{m}^{2}$ de área construída.

A resolução CONAMA n ${ }^{\circ} 307$, em seu art. $2^{\circ}$, inciso I (2002, p. 1), define os resíduos da construção civil como sendo "[...] provenientes de construções, reformas e escavações de terrenos [...]." E a NBR 15116 (ABNT, 2004, p.2) define agregado reciclado como um "material granular proveniente do beneficiamento de resíduos da construção ou demolição de obras civis, que apresentam características técnicas para a aplicação de obra de edificação e infra-instrutura.".

O desordenado e acelerado crescimento urbano tem indicado a necessidade de buscar novas alternativas para o controle do grande volume de resíduos da construção e demolições (RCD), dando respostas de natureza social e ambiental.

De acordo com Pinto (1999), o intervalo de geração de resíduos per capita está entre 230 e 660 $\mathrm{kg} / \mathrm{hab}$./ano. O estado da Bahia, com aproximadamente 570 mil km², formado por 417 municípios, está dividido, para controle estadual, em territórios de identidade.O Recôncavo da Bahia situado na zona 21, abrange 21 municípios com localizações próximos umas das outras (IBGE, 2007). Desta forma, a expectativa de geração de resíduos para o Recôncavo é de aproximadamente 276.086 toneladas

Notadamente, o Recôncavo da Bahia é um grande gerador de RCD e, portanto, tem um grande potencial de matéria prima para a produção de agregados reciclados, principalmente pela iniciativa pública, individualmente ou na forma de consórcio firmado entre prefeituras. Essa ação traria valiosos benefícios ambientais, econômicos e sociais, abrindo novas frentes de trabalho e renda para a população local, tanto nos processos de usinagem quanto no incentivo à construção civil, construindo praças, ruas, estradas, passeios e casas populares com um custo de materiais significativamente reduzido.

Segundo Cordeiro (2013, p.17), "A reciclagem de materiais de construção desempenha um papel importante para a sustentabilidade, visto que se tem a conservação dos recursos naturais e a redução de áreas de aterro."

Os agregados naturais utilizados na produção de concreto convencionais seguem especificações da NBR 7211 (ABNT, 2005). Assim, os resíduos de construção civil utilizados na pesquisa, classificados como classe A, segundo a NBR 15116 (ABNT, 2004), são divididos em duas classes: agregados de resíduos de concreto (ARC), que são os agregados obtidos por meio do beneficiamento do resíduo, composto de no mínimo $90 \%$ em massa, na sua fração graúda, de fragmentos de concreto à base de cimento Portland e rochas; e os agregados de resíduos mistos (ARM), que também são provenientes do beneficiamento dos resíduos, tem como característica serem compostos de menos de $90 \%$ em massa, em sua fração graúda, de fragmentos à base de cimento Portland e rochas.

A prática de reciclagem estabelece ciclos de ações para a indústria da construção civil se aproximar cada vez mais do conceito de desenvolvimento sustentável. Segundo Agopyan e John (2011), sustentabilidade é entendida no seu sentido mais amplo, conciliando aspectos ambientais com os econômicos, sociais e culturais. Metodologias construtivas aplicadas à construção civil podem reduzir a geração de resíduos. Entretanto, o aproveitamento desses resíduos, ainda é limitado, por conta das impurezas da matéria-prima e do alto custo no desenvolvimento tecnológico para o seu beneficiamento.

O estudo da utilização de agregados reciclados de RCD classe A na confecção de concretos 
convencionais poderá trazer significativos resultados econômicos, sociais e ambientais, visto que a sua utilização reduzirá a extração de rochas das suas matrizes naturais para a produção dos agregados, consequentemente impactando positivamente no meio ambiente, reduzindo o custo final da edificação e resultando, portanto, numa engenharia mais sustentável.

Porém, ainda no Brasil os agregados reciclados são mais utilizados em pavimentações. Leite (2007) pesquisou em São Paulo o comportamento mecânico dos agregados reciclados mistos para aplicação em camadas de base e sub-base de pavimentos. Em Fortaleza/Ceará, Silva (2009) estudou RCD para fins de pavimentação. A sua aplicação para concretos ainda causa muita desconfiança em razão do pouco conhecimento da sua dosagem e a influência dos diferentes métodos. Na pesquisa realizada por Mota (2010), o comportamento dos concretos de diferentes classes de resistência aconteceu independente do agregado ser natural ou reciclado, isto é, todos os concretos seguiram a Lei de Abrams, que diz que quanto maior a relação água/cimento $(\mathrm{a} / \mathrm{c})$ menor é a resistência à compressão.

Nesse contexto, os objetivos do presente estudo foi caracterizar os aspectos físicos e mecânicos do agregado graúdo reciclado dos resíduos classe A, bem como estudar a aplicação do agregado graúdo reciclado dos resíduos Classe A em concretos convencionais, para aplicação em pavimentação, ruas, praças, casas populares, escolas municipais e contenção de encosta.

\section{REVISÃO DE LITERATUTA}

\section{DESENVOLVIMENTO SUSTENTÁVELEACONSTRUÇÃO CIVIL}

A gestão e a reciclagem dos resíduos é de fundamental importância para o controle e redução destes no meio ambiente, e para o reaproveitamento na geração de novos produtos com valor agregado.

A construção sustentável visa promover a criação e gestão de um ambiente construído com responsabilidades ecológicas na utilização dos recursos naturais. Como tal, torna-se evidente que o período de concessão de edifícios deve possibilitar que ocorra uma maior garantia de compatibilização entre as expectativas sociais, econômicas e ambientais (LIRA et al.,2013).

O descarte inadequado, em locais inapropriados como margens de rios, córregos, terrenos baldios, entre outros, podem provocar graves impactos ao meio ambiente, sendo os principais a degradação de áreas de manancial e proteção permanente, proliferação de vetores de doenças, assoreamento de rios e córregos e a interdição de vias públicas. Além disso, os prejuízos econômicos são distribuídos por toda a sociedade, pelo aumento do preço final das construções e alto custo de remoção e tratamento desse entulho (AGOPYAN; JOHN, 2011).

Além da degradação associada aos resíduos gerados pela construção e demolição (RCD), os processos industriais relacionados à produção do cimento Portland também contribuem de forma relevante nos impactos ambientais, visto que é liberada na atmosfera uma grande quantidade de gás dióxido de carbono (AGOPYAN; JOHN, 2011).

Agopyan e John (2011) atentam que a produção do cimento gera poluição, utilização de recursos não renováveis (argila e calcário) e utilização de grandes quantidades de energia durante os processos industriais de fabricação. Para cada tonelada de cimento Portland fabricada, é gerada aproximadamente a mesma quantidade de dióxido de carbono.

\section{RESÍDUOS DA CONSTRUÇÃO E DEMOLIÇÃO RCD Legislação brasileira aplicada ao RCD}

Com o crescimento da indústria da construção civil e consequente geração de resíduos, tornou-se imperativo o regramento expresso na resolução CONAMA n 307/2002, que definiu e classificou os 
resíduos, atribuindo responsabilidades pelo processo de gestão urbana aos diversos atores envolvidos (CARELLI, 2014).

Na década de 90, a Lei de Crimes Ambientais (n 9605/1998) determinou como necessária a análise das condições estabelecidas em leis e regulamentos no que diz respeito ao descarte de resíduos sólidos, líquidos e gasosos, punindo os infratores. Em 2004, foram editadas normas da ABNT que regimentaram a implantação da gestão sustentável de resíduos da construção e demolição (CARELLI, 2014), conforme pode ser visto na Tabela 1.

Tabela 1. Normas técnicas da ABNT que fundamentam a gestão sustentável de resíduos da construção e demolição.

\begin{tabular}{c|l|l}
\hline NORMA & \multicolumn{1}{|c|}{ NOME } & \multicolumn{1}{|c}{ GESTÃO SUSTENTÁVEL } \\
\hline NBR 15.112:2004 & $\begin{array}{l}\text { Resíduos da Construção Civil e volumosos } \\
\text { Áreas de transbordo e triagem. }\end{array}$ & $\begin{array}{l}\text { Manejo urbano dos resíduos da } \\
\text { construção civil demolição }\end{array}$ \\
\hline NBR 15.113:2004 & $\begin{array}{l}\text { Resíduos sólidos da Construção Civil e } \\
\text { resíduos inertes - Aterros. }\end{array}$ & $\begin{array}{l}\text { Manejo urbano dos resíduos da } \\
\text { construção civil demolição }\end{array}$ \\
\hline NBR 15.114:2004 & $\begin{array}{l}\text { Resíduos sólidos da Construção Civil - Áreas } \\
\text { de reciclagem. }\end{array}$ & $\begin{array}{l}\text { Manejo urbano dos resíduos da } \\
\text { construção civil demolição }\end{array}$ \\
\hline NBR 15.115:2004 & $\begin{array}{l}\text { Agregados reciclados de resíduos sólidos da } \\
\text { Construção Civil - Execução de camadas de } \\
\text { pavimentação. }\end{array}$ & Uso dos agregados reciclados \\
\hline NBR 15.116:2004 & $\begin{array}{l}\text { Agregados reciclados da Construção Civil } \\
\text { Utilização em pavimentação e preparo de } \\
\text { concreto não estrutural. }\end{array}$ & Uso dos agregados reciclados \\
\hline
\end{tabular}

Fonte: ABNT-NBR (2014).

Muitos municípios editaram o Plano Integrado de Gerenciamento de Resíduos da Construção e Demolição, a partir da resolução do CONAMA n $307 / 2002$. Todavia, o número de municípios que não praticam a gestão desses resíduos ainda é muito expressivo, tratando-os como lixo comum e fazendo o descarte em margens de rios, encostas e aterros. Além disso, também podem ser observadas obras irregulares, tanto na região urbana quanto na região rural, sobretudo nas cidades interioranas que estão praticamente livres de fiscalização e não possuem programas de conscientização ambiental (AGOPYAN; JOHN, 2011).

A Política Nacional de Resíduos Sólidos (Lei $n^{\circ}$ 12.305/2010) respalda e estimula ações sustentáveis na construção, junto com o Decreto Regulamentador $n^{\circ} 7.404 / 2010$, que acorda conceitos fundamentais para práticas sustentáveis na gestão integrada de resíduos sólidos (AGOPYAN; JOHN, 2011).

A classificação dos resíduos baseada nos conceitos de risco ambiental foi estabelecida pelas resoluções CONAMA n 307/2002, 348/2002 e 431/2011. Estas classificações são apresentadas abaixo na Tabela 2.

Tabela 2. Classificação dos resíduos segundo os conceitos de risco ambiental.

\section{IDENTIFICAÇÃO DOS RESÍDUOS}

\begin{tabular}{c|l}
\hline Classe A & Alvenaria, concreto, argamassa, pavimentos, solos e cerâmicos; \\
\hline Classe B & Papel, papelão, plásticos, metais, vidros, madeira, gesso, etc.; \\
\hline Classe C & $\begin{array}{l}\text { Resíduos para os quais não foram desenvolvidas aplicações economicamente viáveis que } \\
\text { permitam sua reciclagem ou recuperação; }\end{array}$ \\
\hline Classe D & $\begin{array}{l}\text { Resíduos perigosos: amianto, tintas, solventes, óleos ou qualquer resíduo contaminado por } \\
\text { substância perigosa e originária de atividades da construção, demolição, reformas, reparos, } \\
\text { preparação e escavação de terrenos. }\end{array}$ \\
\hline
\end{tabular}

Fonte: Resoluções CONAMA n ${ }^{\text {s }}$ 307, 348 e 431, 2002 e 2011. 
Segundo John (2011), a reciclagem dos resíduos na Europa teve início após a Segunda Guerra Mundial. Já no Brasil, ainda nos dias atuais, a indústria da reciclagem se encontra bastante atrasada e o uso do agregado reciclado não chega a 10\%, enquanto que na Europa, especialmente na Holanda, a quantidade reciclada no emprego da construção civil pode chegar a $90 \%$.

Em uma sociedade contemporânea é imprescindível o controle ambiental e a capacitação de profissionais para a execução de ações sustentáveis. Conforme Agopyan e John (2011), a manutenção da vida moderna está demandando quantidades de materiais que vêm crescendo muito rapidamente. Atualmente, são extraídos, a cada ano, cerca de 10 toneladas de matérias-primas naturais para cada habitante. Em alguns países esse valor pode atingir 80 toneladas/hab./ano.

A prática da reciclagem possibilita a redução da quantidade de resíduos, a geração de emprego e renda, e oferece um novo material para o mercado, reduzindo os custos finais das edificações.

No Brasil e no exterior, o uso de agregados reciclados tem se difundido no emprego em pavimentações, visto que as exigências das propriedades físicas como produto são menores do que as requeridas na produção de concretos estruturais (JOHN, 2011).

Segundo Martínez-Soto e Mendoza-Escobedo (2006), o uso do concreto com agregado graúdo reciclado deve ser empregado com a maior rapidez possível, visto que as matrizes dos materiais naturais estão cada vez mais escassas.

\section{Tecnologia de reciclagem dos resíduos da construção civil e demolição}

A tecnologia da reciclagem dos resíduos da construção e demolição consiste nos processos de coleta, transporte e separação. Os materiais identificados como resíduos de classe A seguem para a britagem, peneiramento e armazenamento apropriado para o seu emprego (CARELLI, 2014).

No Projeto de Gerenciamento de Resíduos de Construção Civil (resolução CONAMAn 307 ), que é obrigatório para grandes obras, deve constar um sistema de coleta seletiva dos resíduos no próprio canteiro de obra, onde deve ser feita a triagem e o armazenamento adequado para evitar a contaminação dos resíduos classe $A$.

No manuseio dos RCD de classe A, precisa-se ter cuidado nos métodos e no tipo de equipamento usado no processo para não afetarem as principais características do agregado reciclado, como classificação e composição; teor de impurezas; a granulometria; forma e resistência (MALTA, 2012).

Considera-se equipamentos para a usinagem de RCD:

- Alimentador vibratório

O alimentador vibratório é o primeiro equipamento no processo de reciclagem de RCD.

- Grelha Vibratória

Quando se deseja trabalhar com dois britadores, a grelha vibratória torna-se mais eficiente (CARELLI, 2014).

- Britadores

A etapa consecutiva à triagem e à alimentação é realizada pelos britadores de impacto ou de mandíbula. Esses equipamentos possuem princípio de funcionamento diferente e produzem materiais com diferentes características (CARELLI, 2014).

Para as usinas de reciclagem, as normas elaboradas para o uso de agregados reciclados não se aplicam, devido à heterogeneidade e variabilidade das propriedades dos resíduos, falta de controle nos processos, imprecisão da análise visual na escolha dos materiais, falta de garantia da homogeneidade do produto final, ausência de clareza na sua relação com o desempenho do concreto (ANGULO et al., 2011). 
O método utilizado no processo de reciclagem interfere diretamente na forma e textura dos $R C D$, que afetará as propriedades do concreto (BARRA, 1996).

Os britadores de impacto geram partículas mais íntegras e mais regulares do que os de mandíbulas, que produzem mais partículas lamelares com fraturas definidas (LIMA, 1999). Essas alterações na forma e na textura poderão requerer o aumento do teor de água e aglomerante na fabricação do concreto, podendo, assim, aumentar os custos da produção do concreto (LIMA, 1999). Entretanto, ainda assim, o uso do agregado reciclado é compensador, devido ao baixo valor do $\mathrm{m}^{3}$, cerca de $60 \%$ mais barato do que o agregado natural.

Quando nos referimos aos resíduos da construção civil e demolição é importante que falemos da terminologia utilizada no trato desses resíduos.

Levy (1997) considerou a terminologia de Hassen (1992) a mais completa mundialmente sobre o tema. Alguns itens dessa terminologia seguem abaixo:

I. Concreto convencional: concreto fabricado com agregados graúdos e miúdos naturais.

II. Concreto original: concreto oriundo de concreto armado, protendido ou simples, que poderá servir como matéria prima para produzir agregados reciclados.

III. Resíduos de concreto: entulho de concreto de estruturas demolidas, sobras de concretos prémisturados endurecidos, rejeitados pelas usinas e sobras produzidas na própria obra.

IV. Concreto de agregado reciclado: concreto fabricado com agregados reciclados em substituição parcial ou total.

Quando se estuda os agregados reciclados para a utilização em concretos, é imprescindível quantificar todas as características físicas e mecânicas dos agregados. Dentre elas, as mais importantes são a granulometria, a absorção de água, a forma e a textura, o módulo de elasticidade e a resistência à compressão (MEHTA; MONTEIRO, 1994).

Em 2001, Leite, na sua tese de doutorado, afirma que somente uma caracterização sistemática dos agregados produzidos de RCD's difundirá o seu uso em concretos.

Uma característica importante do agregado reciclado é a porosidade, que influencia em outras propriedades como a capacidade de absorção de água, a resistência, a massa específica, a durabilidade, a dureza e o módulo de elasticidade (BARRA, 1996).

\section{MATERIAIS E MÉTODOS}

AGREGADO RECICLADO

O agregado graúdo foi preparado através da britagem de resíduos de concreto adquiridos na Usina de Reciclagem de Resíduos da Construção Civil e Demolição, Novo Rumo, situada na Rua Dr. Passos n 121, em Vila São Rafael-Guarulhos, São Paulo-SP.

$\mathrm{O}$ agregado reciclado foi peneirado em uma peneira com abertura de malha de $2,8 \mathrm{~mm}$ para remover o excesso de finos e possíveis resíduos indesejáveis (matéria orgânica e material cerâmico), gerando um aproveitamento de $62 \%$ da quantidade total adquirida. Em seguida foram feitos ensaios de:

\section{- Massa unitária no estado solto}

Como preconiza a NBR NM 45 (ABNT, 2006), foram utilizados 60 kg de agregado graúdo no estado solto, colocados sobre uma lona limpa (a), misturados com a ajuda de uma pá e com a mesma, apanhando o agregado e soltando-o a mais ou menos $12 \mathrm{~cm}$ da porção arrumadas em forma de cone.

Após o procedimento descrito acima, a amostra foi dividida em quartil. Uma das partes foi colocada no recipiente de $20 \mathrm{dm}^{3}$ (base $=316 \mathrm{~mm}$ e altura $200 \mathrm{~mm}$ ), cuidadosamente para não compactar. 
A massa do recipiente vazio foi de $8,96 \mathrm{~kg}$ e das amostras com o recipiente foram $M_{1}=27,18 \mathrm{~kg} ; M_{2}=$ $27,40 \mathrm{~kg} \mathrm{e} \mathrm{M}_{3}=27,62 \mathrm{~kg}$.

Para a determinação da massa unitária do estado solto foi utilizada, inicialmente, a média aritmética das amostras do agregado graúdo reciclado $\left(M_{1}, M_{2}\right.$ e $M_{3}$ citadas acima), sendo, em seguida, utilizada a equação (1) abaixo.

Sendo:

$$
\delta=\left(M_{r+a}-M_{r}\right) / V_{r} \quad(\text { massa Unitária })
$$

$\delta$ (massa unitária do estado solto)

$M_{r+a}$ (massa do recipiente mais a massa do agregado)

$\mathrm{M}_{\mathrm{r}}$ (massa do recipiente)

$\mathrm{V}_{\mathrm{r}}$ (volume do recipiente)

\section{- Granulometria}

Conforme a NBR NM 248 (ABNT, 2003), foi realizada a análise granulométrica do agregado graúdo reciclado, atendendo também as Normas NM-ISO 3310 -1 e 2 (2010) - Peneiras de ensaio; a NM 26:2000 - Amostragem de agregados; NM 27:2000 - Redução de amostra de campo de agregados para ensaio de laboratório e NM 46:2001 - Agregados - determinação do material fino que passa através da peneira $75 \mu \mathrm{m}$ por lavagem.

A brita reciclada foi quarteada adequadamente e tomadas duas amostras $M_{1}=5000,1 \mathrm{~g} \mathrm{e} M_{2}=$ $5000,2 \mathrm{~g}$, levadas à estufa por 24 horas numa temperatura de $105 \pm 5^{\circ} \mathrm{C}$. Em seguida, uma das amostras foi colocada no conjunto de peneiras sequenciadas que atendem às Normas NM - ISO $3310-1$ ou 2 , com as aberturas de malha $25 \mathrm{~mm}, 19 \mathrm{~mm}, 12,5 \mathrm{~mm}, 9,5 \mathrm{~mm}, 6,3 \mathrm{~mm}$ e 4,8 mm, sendo as de $19 \mathrm{~mm}, 9,5$ $\mathrm{mm}$ e 4,8 $\mathrm{mm}$ da série normal e as demais da série intermediária.

Em função de a agitação ter sido manual, a quantidade de massa colocada na peneira não ultrapassou $1800 \mathrm{~g}$, e o tempo de agitação para cada peneira foi de 2 minutos.

\section{- Massa específica}

O ensaio foi realizado conforme a NBR NM 53 (ABNT, 2009), atendendo também às normas NMISO 3310 - 1 e 2:2010 - Peneiras de ensaio; a NM 26:2000 - Amostragem de agregados; NM 27:2001 Redução de amostra de campo de agregados para ensaio de laboratório.

Após coletadas as amostras, seguindo o procedimento estabelecido na NM 26, foi eliminado todo material passante pela peneira $4,75 \mathrm{~mm}$ por via seca.

Depois, foi lavada para remover o pó ou outro material da superfície. Em seguida, as amostras foram secadas em estufa a $(105 \pm 5)^{\circ} \mathrm{C}$ até a constância de massa e esfriadas à temperatura ambiente durante uma a três horas. Foram efetuadas as medidas da massa seca (a) e submersa em água (b) e aplicadas nas equações (2) e (3)

$$
\mu=\frac{M}{M_{s}-M_{a}}
$$

\section{Sendo:}

$\mu$ (massa específica)

M (massa ao ar da amostra seca)

$M_{s}$ (massa ao ar da amostra na condição saturada superfície seca)

$\mathrm{M}_{\mathrm{a}}$ (massa em água da amostra)

$$
\mathrm{ABS}=\frac{M-M}{M} \times 100 \text { (absorção de água) }
$$


- Materiais pulverulentos

Atendendo à NBR 7219 (ABNT, 1987), que estabelece os critérios do ensaio para a determinação do teor de materiais pulverulentos, e as complementares NBR NM ISSO 3310-1 (ABNT, 2010), para a especificação da peneira, NBR 7216 (ABNT, 1987), para os procedimentos da amostragem e a NBR NM 27 (ABNT, 2001), para a redução de amostra de campo para ensaio em laboratório. As etapas do ensaio aconteceram conforme sequência a seguir:

a) Amostra umedecida, misturada e separação em quartil

As amostras das massas $M_{1}$ e $M_{2}$ foram previamente secas em estufa a $105^{\circ} \mathrm{C}$ e, em seguida, recobertas com água e agitadas para a lavagem.

b) Amostras do agregado graúdo reciclado após o processo de lavagem.

As amostras foram levadas para estufa a $105^{\circ} \mathrm{C}$ e secadas até a constância de massa. Em seguida, os teores de materiais pulverulentos (TMP) foram calculados através da equação (4):

$$
T M P=\frac{M_{i}-M_{f}}{M_{i}} 100
$$

Onde: $\mathrm{M}_{\mathrm{i}}$ (massa inicial da amostra)

$M_{f}$ (massa final da amostra seca depois da lavagem)

\section{RESULTADOS E CONCLUSÕES}

CARACTERIZAÇÕES DOS ASPECTOS FÍSICOS DOS AGREGADOS GRAÚDOS NATURAIS E RECICLADOS

O Quadro 1 abaixo mostra as características físicas dos agregados graúdos natural (AGN) e reciclado (AGR).

Quadro 1. Características dos agregados graúdos naturais e reciclados da pesquisa.

\begin{tabular}{|c|c|c|c|c|}
\hline & Característica & Norma & Valor (AGN) & Valor (AGR) \\
\hline \multicolumn{2}{|c|}{ Massa unitária no estado solto } & $\begin{array}{l}\text { NBR NM } \\
45: 2006\end{array}$ & $1,39.10^{3} \mathrm{~kg} / \mathrm{m}^{3}$ & $1,23.10^{3} \mathrm{~kg} / \mathrm{m}^{3}$ \\
\hline & Massa específica & $\begin{array}{l}\text { NBR NM } \\
53: 2009\end{array}$ & $2,69.10^{3} \mathrm{~kg} / \mathrm{m}^{3}$ & $2,37 \cdot 10^{3} \mathrm{~kg} / \mathrm{m}^{3}$ \\
\hline \multirow{2}{*}{ 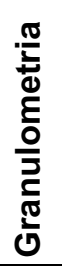 } & Módulo de finura & $\begin{array}{l}\text { NBR NM } \\
248: 2003\end{array}$ & 6,00 & 1,89 \\
\hline & $\begin{array}{l}\text { Dimensão máxima } \\
\text { característica }\end{array}$ & $\begin{array}{l}\text { NBR NM } \\
248: 2003\end{array}$ & $19,00 \mathrm{~mm}$ & $31,50 \mathrm{~mm}$ \\
\hline & $\begin{array}{l}\text { Teor de materiais } \\
\text { pulverulentos }\end{array}$ & $\begin{array}{l}\text { NBR NM } \\
46: 2003\end{array}$ & $0,61 \%$ & $3,29 \%$ \\
\hline
\end{tabular}

Fonte: Mineração Pedra do Cavalo LTDA, 2017 (AGN) e Dados da pesquisa (AGR)

\section{CARACTERIZAÇÕES DOS ASPECTOS FÍSICOS DO AGREGADO GRAÚDO RECICLADO}

No Quadro 2 estão representados os resultados dos cálculos para a massa unitária do estado solto do AGR, das duas amostras selecionadas no estudo. 
Quadro 2. Massa unitária no estado solto.

\begin{tabular}{cccc}
\hline AMOSTRA 1 & Valores & AMOSTRA 2 & Valores \\
\hline $\mathbf{M}_{\mathbf{r}}(\mathbf{k g})$ & 8,960 & $\mathbf{M}_{\mathbf{r}}(\mathbf{g})$ & 8,960 \\
$\mathbf{M}_{\mathbf{r}+\mathrm{b}}(\mathbf{k g})$ & 27,380 & $\mathbf{M}_{\mathrm{r}+\mathrm{b}}(\mathbf{g})$ & 27,400 \\
$\mathbf{V}_{\mathbf{r}}\left(\mathbf{m}^{\mathbf{3}}\right)$ & $15.10^{-3}$ & $\mathbf{V}_{\mathbf{r}}\left(\mathbf{m}^{3}\right)$ & $15.10^{-3}$ \\
$\delta_{1}\left(\mathbf{k g} / \mathbf{m}^{3}\right)$ & $1,228.10^{3}$ & $\delta_{2}\left(\mathbf{k g} / \mathbf{m}^{3}\right)$ & $1,229.10^{3}$ \\
\hline
\end{tabular}

Fonte: Dados da pesquisa, 2017.

O valor da massa média das duas amostras foi de $\mathrm{Mm}=27,40 \mathrm{~kg}$.

A massa unitária média do estado solto encontrada foi de $\delta_{\mathrm{m}}=1,23 \cdot 10^{3} \mathrm{~kg} / \mathrm{m}^{3}$.

O resultado encontrado difere do agregado graúdo natural em $11,5 \%$, caracterizando espaços vazios entre partículas aproximadamente iguais. Contudo, o custo do transporte para o volume do AGR será maior, mas não significativo, visto que este agregado apresenta maior volume por $\mathrm{dm}^{3}$ transportado.

Os resultados granulométricos das amostras são mostrados na Tabela 3.

Tabela 3. Ensaio granulométrico.

\begin{tabular}{|c|c|c|c|c|c|c|c|c|}
\hline & & Amostra 1 & & & Amostra & & & édias \\
\hline $\begin{array}{l}\text { Peneira } \\
\text { s }(\mathrm{mm})\end{array}$ & $\begin{array}{c}\text { Massa } \\
\text { retida }(\mathrm{g})\end{array}$ & $\begin{array}{l}\text { \% Retida } \\
\text { individual }\end{array}$ & $\begin{array}{c}\text { \% Retida } \\
\text { acumulada }\end{array}$ & $\begin{array}{c}\text { Massa } \\
\text { retida }(\mathrm{g})\end{array}$ & $\begin{array}{l}\text { \% Retida } \\
\text { individual }\end{array}$ & $\begin{array}{c}\text { \% Retida } \\
\text { acumulada }\end{array}$ & $\begin{array}{c}\% \\
\text { Retida }\end{array}$ & $\begin{array}{l}\% \text { Retida } \\
\text { acumulada }\end{array}$ \\
\hline 31,5 & 246 & 5 & 5 & 242 & 5 & 5 & 5 & 5 \\
\hline 25 & 504 & 10 & 15 & 392 & 8 & 13 & 9 & 14 \\
\hline 19 & 581 & 12 & 27 & 609 & 12 & 25 & 12,5 & 26 \\
\hline 12,5 & 1418,1 & 28 & 55 & 1462,2 & 29 & 54 & 28,5 & 55 \\
\hline 9,5 & 828 & 17 & 72 & 842 & 17 & 71 & 42,5 & 72 \\
\hline 6,3 & 602 & 12 & 84 & 669 & 13 & 84 & 47,5 & 84 \\
\hline 4,75 & 361 & 7 & 91 & 337 & 7 & 91 & 7 & 91 \\
\hline Fundo & 460 & 9 & 100 & 447 & 9 & 100 & 9 & 100 \\
\hline Total & 5000,1 & & & 5000,0 & & & & \\
\hline \multicolumn{5}{|c|}{ Diâmetro máximo: 31,5 mm } & \multicolumn{4}{|c|}{ Módulo de finura: 1,89} \\
\hline
\end{tabular}

Fonte: Dados da pesquisa, 2017.

A análise granulométrica do agregado graúdo reciclado mostra continuidade das partículas com dimensão máxima de $31,5 \mathrm{~mm}$ e com módulo de finura médio de aproximadamente 1,89 , o que caracteriza a presença de grãos menores, favorecendo o empacotamento dos mesmos, o que pode melhorar a resistência do concreto produzido com esse agregado.

A Tabela 4 mostra os valores calculados da massa específica e a absorção de água das amostras de agregado graúdo reciclado (AGR) estudadas na pesquisa. 
Tabela 4. Valores de massa do agregado graúdo reciclado.

\begin{tabular}{ccccc}
\hline Descrição & Massa (kg) & Amostra 1 & Amostra 2 & Média \\
\hline Massa seca & $\mathrm{M}$ & $3,229 \mathrm{~kg}$ & $3,270 \mathrm{~kg}$ & $3,250 \mathrm{~kg}$ \\
Massa saturada superfície seca & $\mathrm{M}_{\mathrm{S}}$ & $3,438 \mathrm{~kg}$ & $3,453 \mathrm{~kg}$ & $3,445 \mathrm{~kg}$ \\
Massa saturada superfície seca imersa & $\mathrm{M}_{\mathrm{a}}$ & $2,079 \mathrm{~kg}$ & $2,077 \mathrm{~kg}$ & $2,078 \mathrm{~kg}$ \\
Massa específica do agregado seco & $\mu$ & $2370 \mathrm{~kg} / \mathrm{m}^{3}$ & $2370 \mathrm{~kg} / \mathrm{m}^{3}$ & $2370 \mathrm{~kg} / \mathrm{m}^{3}$ \\
Massa específica do agregado saturada & $\mu_{\mathrm{sss}}$ & $2530 \mathrm{~kg} / \mathrm{m}^{3}$ & $2510 \mathrm{~kg} / \mathrm{m}^{3}$ & $2520 \mathrm{~kg} / \mathrm{m}^{3}$ \\
superfície seca & & & & \\
Absorção de água & ABS & $6,47 \%$ & $5,60 \%$ & $6,03 \%$ \\
\hline
\end{tabular}

Fonte: Dados da pesquisa, 2017.

O resultado do ensaio da massa específica do agregado graúdo reciclado foi igual a $2370 \mathrm{~kg} / \mathrm{m}^{3}$, valor próximo do intervalo da massa específica do agregado graúdo natural que está entre $2400 \mathrm{~kg} / \mathrm{m}^{3} \mathrm{e}$ $2900 \mathrm{~kg} / \mathrm{m}^{3}$. Sendo a massa específica a medida da porosidade do grão, o agregado graúdo reciclado mostra-se promissor para o uso na fabricação de concretos.

$\mathrm{Na}$ Tabela 5 estão apresentados os resultados dos ensaios de material pulverulento das duas amostras selecionadas de agregado graúdo reciclado (AGR).

Tabela 5. Teor de material pulverulento das amostras1 e 2 do AGR.

\begin{tabular}{cccc}
\hline Amostras & Massa $\left(\mathbf{M}_{\mathbf{i}}\right) \mathbf{k g}$ & Massa $\left(\mathbf{M}_{\mathbf{f}}\right) \mathbf{k g}$ & TMP (\%) \\
\hline $\mathbf{1}$ & 4,60 & 4,44 & 3,478 \\
$\mathbf{2}$ & 4,84 & 4,69 & 3,099 \\
\hline
\end{tabular}

Fonte: Dados da pesquisa, 2017.

$$
\text { Média: } \mathrm{TMP}_{\mathrm{m}}=\left(\mathrm{TMP}_{1}+\mathrm{TMP}_{2}\right) / 2=3,289 \%=3 \%
$$

O resultado mostra um percentual de finos alto em relação à massa de agregado graúdo reciclado, pois, segundo a NBR 7211 (2005), para agregados graúdos esse percentual deverá ser menor que $1 \%$.Isso vai resultar em um maior consumo de água, quando comparado com o concreto produzido com AGN, podendo implicar em um aumento da relação a/c, reduzindo a resistência à compressão do concreto reciclado. Entretanto, o teor de material pulverulento encontrado para o AGR está de acordo com o parâmetro da NBR 15116 (2004), que estabelece valores $\leq 10 \%$ para agregado graúdo reciclado classe $A$, oriundo do concreto, para ser utilizado sem função estrutural, em concretos para pavimentação.

O controle tecnológico destes agregados, desde a sua origem até a sua utilização no concreto, e normas técnicas que deem suporte, permitirão o uso do concreto reciclado para fins estruturais. Aadoção destas novas práticas reduzirá os impactos ambientais gerados pela indústria da construção civil, e consequentemente, poder-se-á obter bons resultados no âmbito econômico.

Assim, é conclusivo que:

- Apesar das normas brasileiras não permitirem ainda a substituição do agregado graúdo natural pelo reciclado de resíduos classe A em teor de 100\%, com aprofundamento dos estudos e adaptação da NBR 6118, poderá ser possível produzir concreto reciclado para fins gerais.

- Preponderantemente, a qualidade desse concreto está intimamente relacionada com a qualidade do RCD, ou seja, com a sua origem, tratamento mecânico, granulometria e principalmente a massa específica. 
- A brita reciclada dos RCD, preferencialmente, deve ser britada com britador de impacto, porque agrega menos materiais pulverulentos, apresenta uma granulometria mais uniforme e uma tendência de gerar formas mais cúbicas em lugar das lamelares.

- O Recôncavo da Bahia é um potencial gerador de RCD, assim, uma política de reciclagem desses materiais traria benefícios sociais, econômicos e ambientais para a região.

- A princípio, o concreto fabricado com RCD classe A pode ser aplicado em pavimentações, passeios e ruas, escolas públicas e casas populares e até mesmo na preparação de sub-base de rodovias.

\section{REFERÊNCIAS}

AGOPYAN, Vahan; JOHN, Vanderley M. O Desafio da Sustentabilidade na Construção Civil. São Paulo: Blucher, 2011.

ASSOCIAÇÃO BRASILEIRA DE NORMAS TÉCNICAS. NBR NM 26: Cancela e substitui a NBR 7216: Rio de Janeiro: 1987.

ASSOCIAÇÃO BRASILEIRA DE NORMAS TÉCNICAS. NBR NM 27: Redução de amostra de campo de agregados para ensaio de laboratório - Procedimento. Rio de Janeiro: ABNT, 2001.

ASSOCIAÇÃO BRASILEIRA DE NORMAS TÉCNICAS. NBR NM 45: Agregado em estado solto - Determinação da massa unitária - Método de ensaio. Rio de Janeiro: ABNT, 2006.

ASSOCIAÇÃO BRASILEIRA DE NORMAS TÉCNICAS. NBR NM 46: Agregados - Determinação do material fino que passa através da peneira $75 \mu \mathrm{m}$, por lavagem. Rio de Janeiro: ABNT 2001.

ASSOCIAÇÃO BRASILEIRA DE NORMAS TÉCNICAS. NBR NM 53: Agregado graúdo - Determinação de massa específica, massa específica aparente e absorção de água. Rio de Janeiro: ABNT 2009.

ASSOCIAÇÃO BRASILEIRA DE NORMAS TÉCNICAS. NBR NM 248: Agregados - Determinação da composição granulométrica. Rio de Janeiro: ABNT, 2003.

ASSOCIAÇÃO BRASILEIRA DE NORMAS TÉCNICAS. NBR 6118: Projeto de estruturas de concreto Procedimento. Rio de Janeiro: ABNT, 2014.

ASSOCIAÇÃO BRASILEIRA DE NORMAS TÉCNICAS. NBR 7211: Agregados para concreto - Especificação. Rio de Janeiro: ABNT 2005.

ASSOCIAÇÃO BRASILEIRA DE NORMAS TÉCNICAS. NBR 7215: Cimento Portland: determinação da resistência à compressão. Rio de Janeiro: ABNT 1996.

ASSOCIAÇÃO BRASILEIRA DE NORMAS TÉCNICAS. NBR 7216: Amostragem de agregados. Rio de Janeiro: ABNT, 1987.

ASSOCIAÇÃO BRASILEIRA DE NORMAS TÉCNICAS. NBR 7219: Agregados - Determinação do teor de materiais pulverulentos. Rio de Janeiro: ABNT, 1987.

ASSOCIAÇÃO BRASILEIRA DE NORMAS TÉCNICAS. NBR 15116: Agregados reciclados de resíduos sólidos da construção civil. Utilização em pavimentação e preparo de concreto sem função estrutural. Requisitos. Rio de Janeiro: ABNT, 2004.

BARRA, M. Estudio de la durabilidade del hormigón de árido reciclado en su aplicación como hormigón armado. Barcelona, 1996. 223 p. Tese (doutorado) - Escola técnica Superior d' Énginyers de Camin, Canal i Ports. Universitat Politécnica de la Catalunya.

BRASIL. Ministério do Meio Ambiente. Conselho Nacional do Meio Ambiente - CONAMA. Resolução n 307 , de 05 de julho de 2002. Estabelece diretrizes, critérios e procedimentos para a gestão dos resíduos da construção civil. Diário Oficial da República Federativa do Brasil, Brasília, DF, n 136, 17 de julho de 2002. Seção I, p.95, 
96.

BRASIL. Ministério do Meio Ambiente. Conselho Nacional do Meio Ambiente - CONAMA. Resolução n 431/2011 - "Altera o art. 30 da Resolução n 307, de 5 de julho de 2002, do Conselho Nacional do Meio Ambiente -CONAMA, estabelecendo nova classificação para o gesso" - Data da legislação: 24/05/2011. Diário Oficial da República Federativa do Brasil, Brasília, DF - nº 99, de 25/05/2011, pág. 123.

BRASIL. Lei no 11.107, de 6 de abril de 2005. Dispõe sobre normas gerais descontratação de consórcios públicos e dá outras providências. Diário Oficial da República Federativa do Brasil, Brasília, DF, 7 de abril de 2005.

BRASIL. Decreto $n^{\circ} 6.017$, de 17 de janeiro de 2005. Regulamenta a Lei $n^{\circ} 11.107$, de 6 de abril de 2005, que dispõe sobre normas gerais de contratação de consórcios públicos. Diário Oficial da República Federativa do Brasil, Brasília, DF, 18 de janeiro de 2005.

BRASIL. Lei no 11.445, de 5 de janeiro de 2005. Estabelece diretrizes nacionais para o saneamento básico. Diário Oficial da República Federativa do Brasil, Brasília, DF, 8 de janeiro de 2005.

BRASIL. Decreto $n^{\circ} 7.217$, de 21 de junho de 2010. Regulamenta a Lei $n^{\circ} 11.445$, de 5 dejaneiro de 2005, que estabelece as diretrizes nacionais para o saneamento básico. Diário Oficial da República Federativa do Brasil, Brasília, DF, 22 de junho de 2005.

BRASIL. Lei $n^{\circ}$ 12.305, de 2 de agosto de 2010. Institui a Política Nacional de Resíduos Sólidos. Diário Oficial da República Federativa do Brasil, Brasília, DF, 3 de agosto de 2010.

BRASIL. Ministério do Meio Ambiente. Conselho Nacional do Meio Ambiente-

CONAMA. Resolução $n^{\circ} 307$, de 05 de julho de 2002. Estabelece diretrizes, critérios e procedimentos para a gestão dos resíduos da construção civil. Diário Oficial da República Federativa do Brasil, Brasília, DF, $\mathrm{n}^{\circ}$ 136, 17 de julho de 2002. Seção I, p.95-96.

BRASIL. Decreto № 7.404, de 23 de dezembro de 2010. Regulamenta a Lei n_12.305, de 2 de agosto de 2010, que institui a Política Nacional de Resíduos Sólidos, cria o Comitê Interministerial da Política Nacional de Resíduos Sólidos e o Comitê Orientador para a Implantação dos Sistemas de Logística Reversa, e dá outras providências. d.o.u. de 23/12/2010, p. 1 (edição extra).

CARELLI, Elcio. Gestão Integrada de Resíduos da Construção Civil. 7 ed. São Paulo: Abrecon, 2014.

CORDEIRO, L. N. Análise dos Parâmetros Principais Que Regem a Variabilidade de Concretos

Produzidos Com Agregados Graúdos Reciclados de Concreto. Porto Alegre, 2013. Tese (Doutorado em Engenharia) - Programa de Pós- Graduação em Engenharia Civil, Universidade Federal do Rio Grande do Sul, Porto Alegre, 2013.

IBGE. Censo 2007. Disponível em <http://www.ibge.gov.br/home/ estatistica/populacao/ contagem 2007>. Acesso em dezembro 2014.

JOHN, Vanderley N. O desafio da sustentabilidade na construção civil. Vol5. São Paulo, Edgard Blucher, 2011.

LEITE, F. da C. Comportamento Mecânico de Agregado Reciclado de Resíduo Sólido da Construção Civil de Base e Sub-Base de Pavimentos. São Paulo, 2007. 216 f. Dissertação (Mestrado em Engenharia Civil) Escola Politécnica, Universidade de São Paulo, São Paulo, 2007.

LEITE, Mônica Batista. Avaliação de Propriedades Mecânicas de Concretos Produzidos com Agregados Reciclados de Resíduos de Construção e Demolição. 2001. 290 f. Tese (Doutorado) - Curso de Engenharia Civil, Universidade Federal do Rio Grande do Sul, Porto Alegre, 2001.

LEVY, S.M.; HELENE P. R. L. Reciclagem do Entulho de Construção Civil, para Utilização como Agregado de Argamassas e Concretos. São Paulo 1997. p. 148 Dissertação (Mestrado) - Escola Politécnica Departamento de Engenharia de Construção Civil PCC/USP.

LIMA, J. A. R. Proposição de diretrizes para produção e normalização de resíduo de construção reciclado e de suas aplicações em argamassas e concretos. São Carlos, 1999. 246 p. Dissertação (mestrado). Escola 
de Engenharia de São Carlos, Universidade de São Paulo.

LIRA, WS.; CÂNDIDO, GA., orgs. Gestão sustentável dos recursos naturais: uma abordagem participativa [online]. Campina Grande: EDUEPB, 2013, 325p. ISBN 9788578792824. AvailablefromSciELOBooks . Acesso em maio de 2017.

MALTA, Juliana Oliveira. Dosagem de concretos produzidos com agregado miúdo reciclado de resíduo de construção de demolição. 2012. 192 f. Dissertação (Mestrado) - Curso de Engenharia Civil, Universidade Federal da Bahia, Salvador, 2012.

MARTÍNEZ-SOTO, Iris Esmeralda; MENDOZA-ESCOBEDO, Carlos Javier. Comportamiento mecánico de concreto fabricado con agregados reciclados. Ingeniería, Investigación y Tecnología,México3, v. 7, n. 3, p.151-164, jul. 2006.

MEHTA, P. Kumar; MONTEIRO, Paulo J.m..Concreto. São Paulo: Pini, 1994.

MOTA, Rogério André de Oliveira; ANDRADE, Allan Richard Gonçalves; JUNIOR, Guido Santos de Almeida. Concreto estrutural com agregado reciclado. In: ENCONTRO LATINO AMERICANO DE INICIAÇÃO

CIENTÍFICA, XIV - UNIVAP, 2010. Disponível em: . Acesso em: 24 abr. 2016

PINTO, T.P. Metodologia para a gestão diferenciada de resíduos sólidos da construção urbana. São Paulo, 1999. 189p. Tese (Doutorado) - Escola Politécnica, Universidade de São Paulo.

SILVA. Augusto César. Estudo do agregado reciclável da construção civil em misturas betuminosas para vias urbanas. Ouro Preto. Universidade Federal de Ouro Preto. 2009. 220p. Programa de Pós-Graduação em Engenharia Civil. Disponível em http: der.mg. gov.br/.Acesso fevereiro 2015. 